\title{
Design of Modern Home Core Control System Based on Intelligent Lock
}

\author{
Wei Zeng ${ }^{1, a}$, Yushan $\mathrm{Li}^{2, b^{*}}$, Yini Zhang ${ }^{3, c}$,Shu Ran ${ }^{4, d}$, Qiang Dou ${ }^{5, e}$, \\ And Puyan Chen ${ }^{6, f}$ \\ 1,2,3,4,5,6 Chengdu university of Technology, Information Science and Technology College, \\ Chengdu,Sichuan province,China \\ a914628744@qq.com,b269738776@qq.com, ‘449624328@qq.com, d906601866@qq.com, \\ '945405001@qq.com, ${ }^{\mathrm{f}} 1570616631 @ q q . c o m$
}

Keywords: smart home; STM32; CC2530.

Abstract.This paper introduces a new smart home system with low-power, scalability and highly security. The system takes the relatively high performance STM32 chip as the core of data processing, and integrates high-precision resistive touch screen, ZigBee wireless sensor control network, GPRS remote data transmission module. The intelligent lock whose core algorithm is RSA, as a data processing center, provides a standardized data transformation platform for the system, and transfers the task of acquisition and control to the wireless sensor/controller network node, realizing the flexible expansion of it.

\section{Introduction}

The purpose of putting forward the concept of intelligent household is: "make all communication equipments, household appliances and home security devices, which relate to information in family, connect to a family intelligent system which is used to centralized monitor, control and manage family affairs in another place, while maintaining a harmonious relationship between the house facilities and residential environment"[1].

However, such a convenient science and technological civilization has not gotton a very good popularity, the main reasons are high price, lack a unified standard and protocol, and difficult to install and maintain. This paper shows a design plan of modern home system with high security, low cost, simple installation and strong expansibility.

\section{System Structure}

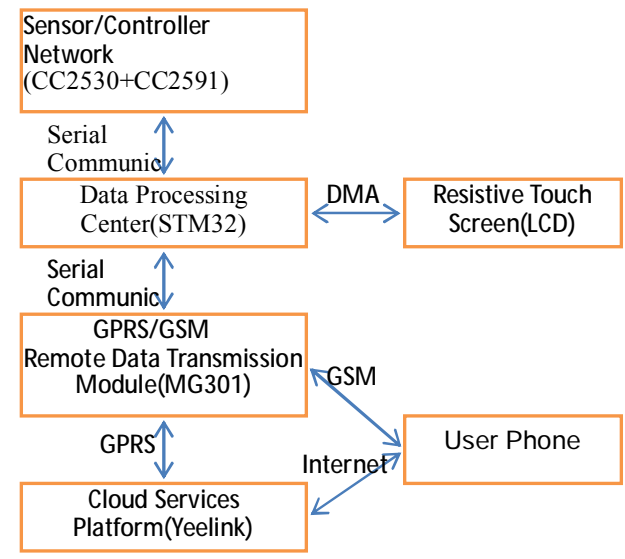

Figure 1 System Structure

This system mainly consists of six parts, which structure is shown in Figure 1, and all parts of the system connect each other via integrated or wireless network, reducing the difficulty of installation . 


\section{Data Processing Center}

\section{Core Processor}

CPU data processing center chooses a low cost, low-power consumption STM32VET6 chip, which is STMicroelectronics (ST). The company introduced a high-performance 32-bit microcontrollers, using high-performance ARM Cortex-M3 32-bit RISC core, operating frequency is $72 \mathrm{MHz}$, computing speed 1.25DMips / MHz [2]. It supports three kinds of power-saving mode, sleep, shutdown and standby mode. standby mode RTC's current consumption is only $3.4 \mathrm{uA}$ under open state.

\section{Power Management}

The system shown is inputted by DC5V 500mA charger, and storaged by $3.6 \mathrm{~V}$ lithium battery. When STM32 detection battery voltage below 3.3V, it enables CN3052A to charge which is a power management chip. Using LDO (linear regulator chip) LP5907MFX-3.3 is to stable output in 3.3V $250 \mathrm{~mA} \mathrm{DC}$ for the data processing center providing energy.

\section{Human-Computer Interaction}

Human-computer interaction provides users with a visual operating environment: firstly it can achieve password lock, doorbell call, password settings and other functions by controlling the 3.2-inch resistive touch screen; secondly can attain unlocking and various alerts via SMS ; thirdly can fulfill sensor data viewing, switch lock, controller operations and other functions via cloud server app or webpage.

\section{Wireless Sensor (/ Controller) Network}

This system uses ZigBee technology[3][4] which is low-cost, low-power, self-configuring, anti-jamming performance, reliable data transmission, network capacity, delay short and safe to construct a cluster-tree Wireless sensor (/ controller) network. In the case of less obstacles and short distance, the route node can be omitted to form a more simple star topology, which can achieve the purpose of saving resources.

Node core microprocessor chooses CC2530F256 chip produced by Texas Instruments (TI).In the harsh operating environment conditions may be added the front-end chip CC2591, which is $2.4 \mathrm{GHz}$ RF produced by TI company. It can not only increase the transmission power, but also to improve the sensitivity of the receiver, thus extending its communication distance [7].

\section{Communication}

The system selects Huawei MG301 module. It based on GPRS CLASS 10, maximum uplink speed $42.8 \mathrm{Kbit} / \mathrm{s}$, the maximum downlink rate of $85.6 \mathrm{Kbit} / \mathrm{s}$, embedded TCP / IP protocol, supports multi-Socket links with operating voltage $3.3 \mathrm{~V}-4.2 \mathrm{~V}$, and two serial interfaces [10], whose price is relatively cheap. The module is fully in line with the system requirements.

In this system, it connects to the Internet through the TCP / IP to issue the data upload and control command, and achieves SMS lock, alarm and reminding functions via communications between the GSM network short message and the user's mobile phone.

\section{Cloud Servers}

It will use the Yeelink networking platform to free for developer in the system development phase, which is provided by Qingdao Yilianke Information Technology Co., Ltd.. The platform can achieve many functions includes the sensor data upload, controller data push, data logging, viewing and operating a mobile phone app, news microblogging push, and so on. 


\section{System Working Principle}

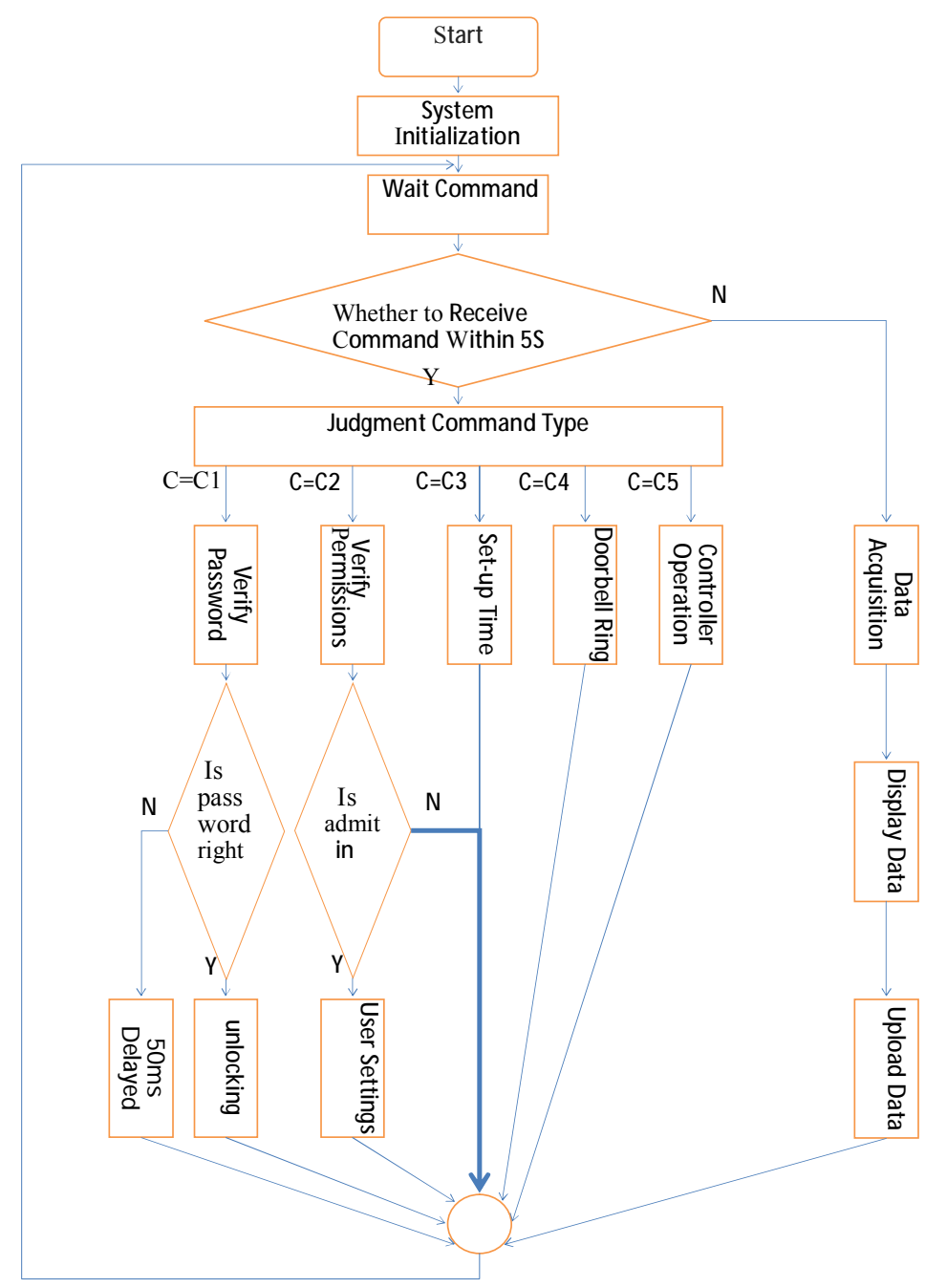

Figure 2 System Work Flow Chart

The system work flow is shown in Figure2, where the $\mathrm{C}$ represents the command received from the data processing center (including the touch screen, GPRS, GSM, etc.. Command priority is $\mathrm{C} 1>\mathrm{C} 2>\mathrm{C} 3>\mathrm{C} 4>\mathrm{C} 5$. When the system is turned on, it is initialized, waiting for the command from the user.

In intelligent lock part, the system only saves RSA algorithm's composite number, 16-bit public key, password encrypted ciphertext, RSA symmetric encryption characteristics and 16-bit key length to ensure the invaders cannot calculated the password from the data of hardware in a short time. After receiving 6-8 digits password and unlock instruction, the public key will encrypt the password, and compare the ciphertext with the text set up by users. If the resulting can not match, it will produce a $50 \mathrm{~ms}$ short delay which human could not distinguish, which greatly prolongs the time of crack the password via brute-forcemethod. It can identify malicious password attacks, access to the operation mode only by highest authority users, and alert the highest authority users by SMS .

Wireless sensor control network based on ZigBee with excellent protocol is the combination of star network and cluster tree topology, which can join the network for only 2-3 seconds after the establishment of a network coordinator as long as the router and terminal node set up a same channel with coordinator and area network identifier, which provides a good scalability for system, so that almost all household electrical devices are available through the system control. And on the hardware design of the link lights, make the connection more reliable and reduce the difficulty of node maintenance. 
For sensor networks, sensor transmits the collected data to the coordinator packaged by user-defined frame format, then the data packet will be send to the data processing center which analysis data packet and then transmit to the cloud server, and the corresponding data will display on the LCD screen.

For the controller network, the data processing center receives the command and then packages it by user-defined frame format, sends to the coordinator demodulation and broadcast in network, and the operation will be completed after the corresponding ID controller recevive the massage.

\section{System Testing}

\section{Wireless Sensor / Control Network Node Power Testing (not including CC2591)}

The wireless sensor / control network node is powered by a $3.6 \mathrm{~V}$ rechargeable lithium battery, and its power consumption is shown in Table 1:

Table 1 Wireless Sensor / Control Network Node Power Condition

\begin{tabular}{|c|c|c|}
\hline $\begin{array}{c}\text { A } \\
\text { Cycle }\end{array}$ & $\begin{array}{l}\text { Operative } \\
\text { Mode }\end{array}$ & $\begin{array}{l}\text { Dormant } \\
\text { State }\end{array}$ \\
\hline Voltage & $3.6 \mathrm{~V}$ & $3.6 \mathrm{~V}$ \\
\hline $\begin{array}{l}\text { Maximum } \\
\text { Current }\end{array}$ & $46 \mathrm{~mA}$ & $3.2 \mathrm{~mA}$ \\
\hline Power & $165.6 \mathrm{~mW}$ & $11.5 \mathrm{~mW}$ \\
\hline
\end{tabular}

ZigBee Wireless Transmission Distance Test (accessibility, not including CC2591)

\begin{tabular}{|c|c|c|c|c|c|c|}
\hline \multicolumn{1}{c}{ Table 2 } & ZigBee Wireless Transmission Distance \\
\hline $\begin{array}{c}\text { Transmission } \\
\text { Distance }(\mathrm{m})\end{array}$ & 10 & 30 & 50 & 100 & 130 & 150 \\
\hline $\begin{array}{c}\text { Data } \\
\text { Transmission }\end{array}$ & Normal & Normal & Normal & Normal & Instable & No signal \\
\hline
\end{tabular}

The test results show that the system can cover the whole family, and realize the coordination of family facilities and family environment under the coordination of routing nodes.

Wireless Sensor / Control Network Node Network Access Permission Testing

\begin{tabular}{|l|c|c|c|c|c|}
\multicolumn{8}{|c|}{ Table 3 Wireless Sensor Control Network Node Access to Network Condition } \\
\begin{tabular}{|l|c|c|c|c|} 
Total Test \\
Times
\end{tabular} & $\begin{array}{c}\text { The Minimum } \\
\text { Admission } \\
\text { Time (s) }\end{array}$ & $\begin{array}{c}\text { The Maximum } \\
\text { Admission } \\
\text { Time (s) }\end{array}$ & $\begin{array}{c}\text { The Average } \\
\text { Access } \\
\text { Time (s) }\end{array}$ & $\begin{array}{c}\text { Network } \\
\text { Failures (t }>20 s)\end{array}$ & $\begin{array}{c}\text { Network } \\
\text { Failure } \\
\text { Rate }\end{array}$ \\
\hline 300 & $1{ }^{\prime} 78$ & 7 '53 & 3 '92 & 5 & $1.67 \%$ \\
\hline
\end{tabular}

GSM Network SMS Unlock Testing

\begin{tabular}{|c|c|c|c|c|c|}
\multicolumn{7}{c|}{ Table 4 GSM Network SMS Unlock Condition } \\
\hline $\begin{array}{c}\text { Total Test } \\
\text { Times }\end{array}$ & $\begin{array}{c}\text { Shortest } \\
\text { Time (s) }\end{array}$ & $\begin{array}{c}\text { Longest } \\
\text { Time }(\mathrm{s})\end{array}$ & $\begin{array}{c}\text { Average } \\
\text { Time( }>300 \mathrm{~s})\end{array}$ & $\begin{array}{c}\text { Failure } \\
\text { Times }\end{array}$ & $\begin{array}{c}\text { Failure } \\
\text { Rate }\end{array}$ \\
\hline 200 & $5 ` 41$ & $183^{\prime} 22$ & $7 ‘ 59$ & 1 & $0.5 \%$ \\
\hline
\end{tabular}

\section{GPRS Network Unlock Testing}

Table 5 GPRS Network Unlock Situation

\begin{tabular}{|c|c|c|c|c|c|}
\hline $\begin{array}{c}\text { Total Test } \\
\text { Times }\end{array}$ & $\begin{array}{c}\text { Shortest } \\
\text { Time (s) }\end{array}$ & $\begin{array}{c}\text { Longest } \\
\text { Time (s) }\end{array}$ & $\begin{array}{c}\text { Average } \\
\text { Time }\end{array}$ & $\begin{array}{c}\text { Failure } \\
\text { Times }(\mathrm{t}>20 \mathrm{~s})\end{array}$ & $\begin{array}{c}\text { Failure } \\
\text { Rate }\end{array}$ \\
\hline 300 & $1^{\prime} 64$ & $11^{\prime} 08$ & $4^{\prime} 63$ & 3 & $1 \%$ \\
\hline
\end{tabular}

\section{Data Monitoring and Testing in the Name of Temperature, Humidity, Combustible Gas}

In this paper, using Xima AS847 as the reference standard, a high precision industrial temperature and humidity meter with temperature error of $+/-1 \mathrm{DEG} \mathrm{C}$ and the humidity of error of $+/-3 \%$, and humidity sensor DHT11, and gas sensor MQ-2. 
Table 6 Sensor Monitoring Situation

\begin{tabular}{|c|c|c|c|c|c|c|c|c|c|}
\hline $\begin{array}{c}\text { Total } \\
\text { Test } \\
\text { Times }\end{array}$ & $\begin{array}{c}\text { Middle- } \\
\text { Temperature } \\
\text { Error }\end{array}$ & $\begin{array}{c}\text { Middle- } \\
\text { Temperature } \\
\text { Error }\end{array}$ & $\begin{array}{c}\text { False } \\
\text { Alarm } \\
\text { Number }\end{array}$ & $\begin{array}{c}\text { False } \\
\text { Alarm } \\
\text { Rate }\end{array}$ & $\begin{array}{c}\text { Omissive } \\
\text { Alarm } \\
\text { Number }\end{array}$ & $\begin{array}{c}\text { Omissive } \\
\text { Alarm } \\
\text { Rate }\end{array}$ & $\begin{array}{c}\text { Minimu } \\
\text { m Alarm } \\
\text { Delay(s) }\end{array}$ & $\begin{array}{c}\text { Maximum } \\
\text { Alarm } \\
\text { Delay(s) }\end{array}$ & $\begin{array}{c}\text { Average } \\
\text { Alarm } \\
\text { Delay(s) }\end{array}$ \\
\hline 200 & $\pm 0.3 \square$ & $2 \%$ & 0 & 0 & 1 & $0.5 \%$ & $2^{\prime} 11$ & $9^{\prime} 45$ & $6^{\prime} 16$ \\
\hline
\end{tabular}

3.7 Home Appliance Controller Testing in the Name of Curtain Motor, Electric Water Heater Relay Switch, S Lighting Switch

\begin{tabular}{|c|c|c|c|c|c|}
\hline \multicolumn{1}{|c|}{ Table 7 } & Controller Control Situation \\
$\begin{array}{c}\text { Curtain Control } \\
\text { Failure Rate (300) }\end{array}$ & $\begin{array}{c}\text { Water Heater } \\
\text { Control Failure } \\
\text { Rate (300) }\end{array}$ & $\begin{array}{c}\text { Lighting } \\
\text { Control Failure } \\
\text { Rate (300) }\end{array}$ & $\begin{array}{c}\text { Control } \\
\text { Minimum } \\
\text { Delay (s) }\end{array}$ & $\begin{array}{c}\text { Control } \\
\text { Maximum } \\
\text { Delay (s) }\end{array}$ & $\begin{array}{c}\text { Control } \\
\text { Average } \\
\text { Delay (s) }\end{array}$ \\
\hline $1 \%$ & $1.33 \%$ & $0.33 \%$ & 1 '39 & $5^{\prime} 73$ & 3 ' 15 \\
\hline
\end{tabular}

\section{Conclusions}

After a thorough theoretical analysis and actual test strictly, the system can achieve the functions of security intelligence lock, home environment monitoring, household equipment control, and freedom of expansion capabilities. It is easy to install for the system integration is relatively high and convenient to maintain for it's clear structure and high degree of freedom nodes. It is suitable for the majority of family for it's low cost, strong interpersonal function, and simple operation. The system also can be transplanted to agricultural automation, intelligent building and the industrial automation with low delay requirement, which has high commercial and practical value.

\section{References}

[1] Zhan Liang. Smart home technology based on ZigBee wireless network system [D]. Master's thesis, Beijing University of Posts and Telecommunications, 2008.(In Chinese)

[2] ST. STM32F103xC,STM32F103xD,STM32F103xE Datasheet[OL].

http://www.st.com/st-web-ui/static/active/en/resource/technical/document/datasheet/CD00191185.p df, 2014.12.

[3]Zhai Lei, Liu Shengde, Hu Xianbin. ZigBee technology and applications. First edition. Beijing: Beijing University of Aeronautics and Astronautics Press, 2007. pp.3-19.(In Chinese)

[4] Huang Jie. Design and implementation of wireless temperature sensor network based on ZigBee[D]. Master's thesis, Northeastern University, 2007.(In Chinese)

[5] Liu Yanfei, Wang Cheng, Yu Chengbo. Research on ZigBee Wireless Sensors Network Based on ModBus Protocol. International Forum on Information Technology and Applications. 2009. pp.487-490.

[6] Texas Instrument. CC2530 Datasheet. 2009.

[7]Zhao Qi, Chen Jiapin, Li Zhenbo. Communication design and microcomputer information (embedded and SOC) of ZigBee based on radio frequency CC2520. 2010,26 (5). Pp.37-38.(In Chinese)

[8] C.Bettstetter,H.J.Vogel,J.Eberspacher.GSM Phase2+,General Packet Radio Service GPRS. Architecture,Protocols and Air Interface,IEEE Communications Surveys, 1999,2(3).

[9] Han Yadong. Research and design of wireless remote monitoring system based on GPRS technology [D]. Master's thesis, Wuhan University of Technology, 2009.(In Chinese)

[10] HUAWEI Technology Co., Ltd., HUAWEI MG301 GSM LCC module hardware guide.2014.(In Chinese) 